\title{
A PESQUISA BIOGRÁFICA OU A CONSTRUÇÃO COMPARTILHADA DE UM SABER DO SINGULAR
}

\section{CHRISTINE DELORY-MOMBERGER}

Université Paris 13 Sorbonne Paris Cité

Tradução do Francês por Eliane das Neves Moura

Departamento de Letras/UFMT - Doutoranda PPGE/UFMT

RESUMO

O artigo buscará revisitar os fundamentos epistemológicos e metodológicos da pesquisa biográfica em Educação a partir de duas questões: Qual o saber que a pesquisa biográfica busca ? Como a pesquisa biográfica constrói este saber? A primeira questão permitirá reafirmar a especificidade e a centralidade do fato biográfico nos processos de individuação e de socialização e interrogar o campo de conhecimento aberto à pesquisa biográfica, descrevendo operações e noções centrais (atividade biográfica, biografização, biograficidade). A segunda questão levará à exploração dos modos de construção de um saber do biográfico que não pode ser, de uma parte, senão que um saber do singular encontrando sua fonte em particular nas narrações individuais, e que não pode se construir, de outra parte, senão na base de uma pesquisa colaborativa na qual estão engajados pesquisadores e pessoas sobre/com as quais eles "pesquisam". Os elementos de resposta trazidos para este duplo questionamento serão enfim mobilizados para tentar esclarecer a compreensão e uso dos termos pesquisa biográfica/pesquisa biográfica em educação para designar nossa corrente de pesquisa.

Palavras-chave: Fato biográfico. Narrativa biográfica. Pesquisa colaborativa. Construção partilhada do saber. Educação

\section{RÉSUMÉ}

\section{LA RECHERCHE BIOGRAPHIQUE OU LA CONSTRUCTION PARTAGÉE D'UN SAVOIR DU SINGULIER}

L'article s'attachera à revisiter les fondements épistémologiques et méthodologiques de la recherche biographique en éducation à partir de deux questions: À quel savoir prétend la recherche biographique? Comment la recherche biographique construit-elle ce savoir ? La première question permettra de réaffirmer la spécificité et la centralité du fait biographique dans les processus d'individuation et de socialisation et d'interroger le champ de connaissance ainsi ouvert à la re- 
cherche biographique, en décrivant les opérations et les notions centrales (activité biographique, biographisation, biographicité). La deuxième question conduira à explorer les modes de construction d'un savoir du biographique qui ne peut être, d'une part, qu'un savoir du singulier trouvant sa source en particulier dans les narrations individuelles, et qui ne peut s'édifier, d'autre part, que sur la base d'une recherche collaborative dans laquelle sont engagés ensemble les chercheurs et les personnes sur/avec lesquelles ils " recherchent ». Les éléments de réponse apportés à ce double questionnement seront enfin mobilisés pour tenter d'éclairer la compréhension et l'usage des termes recherche biographique / recherche biographique en éducation pour désigner notre courant de recherche.

Mots-clés: Fait biographique. Récit biographique. Recherche collaborative. Construction partagée du savoir. Éducation

\section{THE BIOGRAPHY RESEARCH OR THE}

\section{JOINT DEVELOPMENT OF SINGULAR KNOWLEDGE}

This article aims to discuss the epistemic and methodological bases of Biography research in education, throughout two main questions: Which is the knowledge Biography research aims towards? and: How does it develop this knowledge? By describing the operations and key concepts (biographical activity, biographicity, biographization) - the first question will allow us to re-affirm the specificity and the key role of the biography fact within the individuation and socialization processes and to question the knowledge field which thus opens up for the Biography research. The second one, will allow us to explore the way biography knowledge is being developed; a knowledge which can - on one hand - only be singular, emerging especially from individual narratives and - on the other - only be developed on the bases of collaborative research, equally involving researchers and the people they work on/ with. The answer premises to theses questions will finally be mobilized in the attempt to clarify the understanding and use of the terms Biography research and Biography research in education for referring to our research field.

Keywords: Biography fact. Biography narrative. Bollaborative research. Joint development of knowledge. Education.

\section{RESUMEN LA INVESTIGACIÓN BIOGRÁFICA O LA CONSTRUCCIÓN DE UN SABER DEL SINGULAR}

El artículo pretende revisar los fundamentos epistemológicos y metodológicos de la investigación biográfica en Educación a partir de 
dos preguntas ¿Cuál es el saber que la investigación biográfica busca? ¿Cómo la investigación biográfica construye este saber? La primera cuestión permitirá reafirmar la especificidad y la centralidad del hecho biográfico en los procesos de individuación y de socialización e interrogar el campo de conocimiento abierto para la investigación biográfica, describiendo operaciones y nociones centrales (actividad biográfica, biografización, biograficidad). La segunda cuestión llevará a la exploración de los modos de construcción de un saber del biográfico que no puede ser, de una parte, sino un saber del singular, encontrando su fuente en particular en las narraciones individuales, y que no se puede construir, por el contrario, sino sobre la base de una investigación colaborativa en la cual están comprometidos investigadores y personas sobre/con las cuales ellos "investigan". Los elementos de respuesta traídos a este doble cuestionamiento serán en fin movilizados para tratar de aclarar la comprensión y uso de los términos investigación biográfica/ investigación biográfica en educación, para designar nuestra corriente de investigación.

Palabras clave: Hecho biográfico. Narrativa biográfica. Investigación colaborativa, Construcción compartida de saber. Educación.

Quando se trata de "ciência humana", sabe-se apenas com os outros.

(Franco Ferrarotti, 2013b)

Mais uma vez, coloco no centro das nossas discussões e de nossas trocas as questões de epistemologia e de metodologia. É que nós não terminamos ainda de questionar o que fundamenta o projeto e o processo da pesquisa biográfica, de identificar sua especificidade e, portanto, sua autonomia em relação a outras correntes das ciências humanas e sociais. E não se trata tanto de "distinguir" mas de melhor apreender o que é constitutivo da nossa corrente de pesquisa, de melhor representar, para nós mesmos, nossos objetos de conhecimento, as noções que utilizamos, os procedimentos que implementamos.

Proponho-me mais uma vez a retomar essas questões de epistemologia e de método, e a "recolocá-las no canteiro de obras" como dizemos em francês, a partir de duas questões cuja simplicidade de formulação não ocultará seu caráter denso: A qual saber aspira a pesquisa biográfica? E: Como a pesquisa biográfica constrói esse saber?

Digamos também, desde esta introdução, que talvez os elementos de resposta que daremos a essas questões nos levarão a suscitar certa imprecisão no uso e na articulação que fazemos entre pesquisa biográfica e pesquisa biográfica em educação.

\section{A qual saber aspira a pesquisa biográfica?}

Engajar-se na resposta dessa primeira pergunta significa recolocar fundamentalmente o problema do projeto epistemológico da pesquisa biográfica e reafirmar, no cerne deste projeto 
- para dizê-lo desde já e de modo muito sintético - a especificidade e a centralidade do fato biográfico. Não teremos dificuldade em entender que o campo de conhecimento da pesquisa biográfica é o dos processos de constituição individual (de individuação), de construção de si, de subjetivação, com o conjunto das interações que esses processos envolvem com o outro e com o mundo social. Convenhamos, contudo, que a pesquisa biográfica partilha esse campo de investigação com outras correntes de pesquisa como as das sociologias do indivíduo ou da psicologia social, especialmente nas suas versões clínicas. Para dar apenas um exemplo, quem dentre nós poderia "assinar", sob a denominação de pesquisa biográfica, esta definição dada por Florence Giust-Desprairies da psicologia social clínica: "A psicologia social clínica é uma análise dos processos psíquico e sociais, subjetivos e coletivos, pelos quais o sujeito em situação social dá sentido a sua experiência" (GIUST - DESPRAIRIES, 2004, p. 60, grifo nosso)?' Dentro deste campo do conhecimento compartilhado, devemos, portanto, reiterar que a entrada específica da pesquisa biográfica, seu foco e o saber que ela procura diz respeito ao biográfico enquanto dimensão constitutiva da gênese e do tornarse socioindividual.

Como declinar esse saber biográfico? Quais processos singulares constituem o objeto? De que noções centrais permitem dar conta? Mas também quais são as finalidades que prevemos para a pesquisa biográfica, entre conhecimento, ética e política? São todas essas questões - que em si mesmas não são novas - que nos cabe agora responder de forma mais dire-

1 Especialmente quando ela continua: Por essa abordagem, procuro situar a interioridade do sujeito em um contexto, temporalizado e atualizado, de maneira a localizar quais encaminhamentos significativos se formaram e continuam a se construir e, a partir de quais solicitações externas ao sujeito para que este teça a trama renovada de sua relação com ele próprio, aos outros e ao mundo. " (GIUST-DESPRAIRIES, 2004, p. 60) cionada com o propósito de elucidação e de aprofundamento.

\section{Reconhecer o fato biográfico}

A pesquisa biográfica se diferencia de outras correntes de pesquisa por ela introduzir a dimensão do tempo, e mais especificamente a temporalidade biográfica em sua abordagem dos processos de construção individual. O ser humano faz a experiência de si mesmo e do mundo em um tempo que ele relaciona com sua própria existência. A temporalidade biográfica é uma dimensão constitutiva da experiência humana, por meio da qual os homens dão forma ao que vivem. Essa temporalidade biográfica tem sua gramática ou sua sintaxe fundamentada na sequência narrativa matricial que representa a trama da vida entre o nascimento e a morte. A pesquisa biográfica faz assim reflexão da inscrição do agir e do pensar humanos em figuras orientadas e articuladas no tempo que organizam e constroem a experiência segundo a lógica de uma razão narrativa ${ }^{2}$. De acordo com essa lógica, o indivíduo humano vive cada instante de sua vida como o momento de uma história: história de um instante, história de uma hora, de um dia, história de uma vida. Algo começa, se desenrola, chega ao fim, em uma sucessão, uma acumulação, uma sobreposição indefinida de episódios e de peripécias, de provações e de experiências. A dimensão biográfica deve assim ser entendida como uma elaboração cumulativa e integrativa da experiência segundo uma hermenêutica que faz da trama narrativa seu modo de apreensão e de inteligibilidade da vida.

Tal é a realidade que nós poderíamos dizer antropológica do fato biográfico. Os seres humanos não têm uma relação direta, transparente nem com sua vivência e nem com o desenrolar de sua vida; essa relação é

2 "O tempo torna-se tempo humano na medida em que é articulado de maneira narrativa." (RICOEUR, 1983, p. 17). 
mediada pela linguagem e por suas formas simbólicas. Recordaremos a célebre formulação do filósofo alemão Wilhelm Schapp (1992): "Die Geschichte steht für den Mann [A história substitui o homem] $]^{3}$. "A escrita da vida" à qual remete a etimologia da palavra biografia deve ser aqui entendida como uma atitude primeira e específica da vivência humana: antes de qualquer tradução ou expressão de sua existência nas formas verbalizadas, orais ou escritas, os homens configuram mentalmente sua vida na sintaxe da narrativa. A percepção e a inteligência da sua vivência passam por mediações que emprestam uma figura narrativa aos eventos e às situações de sua existência. ${ }^{4}$

Reconhecendo a dimensão constitutiva do fato biográfico no desenvolvimento humano, o saber pretendido pela pesquisa biográfica é o de explorar o espaço e a função do biográfico nos processos complementares de individuação e de socialização, para questionar suas múltiplas dimensões - antropológica, semiótica, cognitiva, psíquica, social -, a fim de ajudar a melhor compreender as relações de produção e construção recíproca dos indivíduos e das sociedades. A categoria biográfica realmente dá acesso ao trabalho de gênese sócio-individual pela qual os indivíduos perlaboram o mundo social e histórico e não cessam de produzi-lo ao produzirem-se a si mesmos.

\section{Descrever a atividade biográfica}

É este trabalho de perlaboração e de gêne-

3 « Die Geschichte steht für den Mann »: " A história substitui o homem » segundo a tradução de J. Greisch, ou « a história responde pelo homem » segundo a de P. Ricoeur (1983, p. 114).

4 São essas mediações que Paul Ricoeur descreveu como resultantes da " estrutura pré-narrativa da experiência temporal »: "Não há experiência humana, observa, que já não seja mediatizada por sistemas simbólicos e, entre eles, por narrativas, [...] Não temos acesso aos dramas temporais da existência fora das histórias contadas a seu respeito por outros ou por nós mesmos.» (RICOEUR, 1983, p. 113.) se que devemos agora precisar, ressituando e descrevendo a atividade biográfica. Precisamos, para isso, retornar às condições nas quais ocorreram as experiências que vivemos (Erlebnis) e a forma pela qual nós as construímos como "experiência" (Erfahrung). Falar sobre a construção da experiência é falar sobre o que está no âmago da atividade biográfica. É falar da maneira pela qual cada um de nós nos apropriamos do que vivemos, experimentamos, conhecemos, pela qual nós o transformamos precisamente em "experiência"

As experiências que vivemos acontecem nos mundos históricos e sociais aos quais pertencemos e trazem, portanto, a marca das épocas, dos meios, dos ambientes nos quais nós as vivemos. De acordo com seus pertencimentos, sua idade, suas categorias sócio-profissionais, suas atividades sociais, os indivíduos atravessam sucessivamente, e algumas vezes simultaneamente, um grande número de espaços sociais e de campos institucionais: família, escola e instituições de formação, mercado de trabalho, profissão e empresa, instituições sociais e culturais, associações e redes de sociabilidade etc. Ora, esses dados sociais "objetivos" não são percebidos como tais na experiência individual e singular que têm deles. Se prestarmos atenção à forma como os indivíduos vivem e experimentam a "realidade social", o que constatamos? 0 modo de presença do indivíduo no mundo social resulta de uma experiência no tempo: o indivíduo vive o espaço social como uma sucessão temporal de situações e de acontecimentos. Para o indivíduo, o mundo social se constitui à medida de suas experiências como uma ordem racional de ações (SCHÜTZ, 1981). Os saberes sociais são organizados na consciência individual como scripts de ação e de "planos de vida". Em particular, os mundos sociais dos quais ele participa são apreendidos por ele sob a forma de programas 
biográficos ou ainda de "biografias típicas" das quais são portadores. Cada espaço social (a família, a escola, a empresa etc.) especifica assim estruturas de ação e perfis biográficos que fazem parte dos saberes transmitidos e são atualizados e experimentados na experiência cotidiana.

Quais são os efeitos dessa "temporalização biográfica" do espaço social? Ela provoca uma transformação na percepção e na construção do mundo social, organizado não mais segundo regras abstratas e formais, mas segundo o ponto de vista e a temporalidade daquele que o atravessa. Portanto, as realidades sociais não existem para o indivíduo como elas podem existir para o sociólogo: elas tomam para ele $o$ aspecto de experiência que ele relaciona consigo mesmo. Na consciência individual, os fatos sociais que determinam as situações, as interações, as trajetórias, tudo o que faz com que a vida de um indivíduo seja atravessada completamente pelo social resulta da lógica das experiências acumuladas e da forma própria que essas experiências imprimem ao sentimento de si próprio e de sua existência.

O indivíduo só pode apreender o social de outra forma, de maneira autorreferencial, em relação com a sua história e suas experiências, nas formas de seu "mundo-de-vida", para retomar o conceito desenvolvido por Alfred Schütz (1981), ou ainda, de acordo com a bela expressão dos sociólogos alemães Peter Alheit e Bettina Dausien, construindo "o mundo interior do mundo exterior" (2000, p. 276). o que faz surgir essa lógica de subjetivação e de apropriação biográfica é a dimensão socializadora da atividade biográfica, o papel que ela desempenha na forma como os indivíduos compreendem a si mesmos e se estruturam numa relação de coelaboração de si e do mundo social. A atividade biográfica realiza assim uma dupla e complementar operação de subjetivação do mundo histórico e social e da socialização da experiência individual: ela é ao mesmo tempo e inseparavelmente aquilo por que os indivíduos se constroem como seres singulares e é por isso que se produzem como seres sociais.

$\mathrm{Na}$ sua dimensão sociohistórica, a atividade biográfica pode ser descrita como um conjunto de operações mentais, verbais, comportamentais, pelas quais os indivíduos se inscrevem subjetivamente nas temporalidades históricas e sociais que lhes antecedem e os ambientam, apropriando-se das sequências, dos programas e dos padrões biográficos formalizados (currículo escolar, currículo profissional, mas também scripts de ação e cenários) dos mundos sociais dos quais eles participam. Consequentemente, ela surge como um processo essencial de constituição do indivíduo em sociedade. A categoria biográfica poderia ser definida como uma categoria da experiência que permite ao indivíduo, nas condições de sua inscrição sociohistórica, integrar, estruturar, interpretar situações e os acontecimentos da sua vivência. Segundo as épocas e as formas societais, as manifestações da atividade biográfica e a intensidade do trabalho que lhe corresponde variam em função do recurso diferenciado que as sociedades fazem à reflexividade individual e a esse campo privilegiado de reflexividade que constitui a construção biográfica.

\section{Analisar o processo de biografização}

A pesquisa biográfica analisa os processos conjuntos de individuação e de socialização que são constitutivos da construção e do desenvolvimento sócio-individual como formas de apropriação e de configuração biográfica. É para caracterizar este processo de apropriação/configuração pelo qual o indivíduo produz, para ele como para os outros, as manisfestações, o sentido e a forma de sua existência que 
a pesquisa biográfica recorre ao neologismo biografização. Estamos constentemente relatando a nós mesmos as situações nas quais estamos envolvidos e fazemos dessas situações nossa experiência; cada momento, cada espaço em que vivemos, nós os transformamos no momento e no lugar de uma história singular que é a nossa história: na realidade, estamos constantemente nos biografando, isto é, inscrevendo nossa experiência nos esquemas temporais orientados que organizam mentalmente nossos gestos, nossos comportamentos, nossas ações de acordo com uma lógica de configuração narrativa.

Denominaremos biografização o conjunto das operações e dos comportamentos pelos quais os indivíduos trabalham para se dar uma forma própria na qual eles se reconhecem a si mesmos e se fazem reconhecer pelos outros. Esta tomada de forma tem uma dimensão reflexiva e autorreferencial no sentido em que ela consiste em relatar as situações, os acontecimentos dentro de um si mesmo. Neste sentido, a biografização surge como uma hermenêutica prática, um quadro de estruturação e de significação da experiência exercendo-se de forma constante na relação do homem com a sua vivência e com seu ambiente social e histórico.

Quais são as formas que toma esta metabolização da experiência? Se a fala de si, na forma particular da narrativa de vida, oral ou escrita, é uma modalidade privilegiada dessas operações de biografização - aquela que corresponde mais visivelmente a esse processo da escrita de si e the constitui a forma mais elaborada -, é necessário acrescentar-lhe muitas outras formas mentais e comportamentais, a começar pela aparência física que exibimos de nós mesmos (cuidados corporais, roupas, ornamentos), nossas maneiras de ser pública e privada, o modo como falamos, nossas formas de "morar", nossos modos de sociabilidade e de relacionamento etc.
Todas essas manifestações de si, implícitas ou explícitas, conscientes ou inconscientes, participam do sentimento unitário e integrado que temos de nós mesmos (ipséité) em relação com a uniformidade de nossa existência através do tempo, e contribuem para forjar o que Ricoeur chama de nossa "identidade narrativa"5, ou seja, esta imagem que construímos de nós mesmos pela mediação narrativa, incorporada em um estilo, uma maneira de ser, um modo de aparência.

Essas operações de biografização se inscrevem em um processo constante e cumulativo de estruturação e de interpretação da experiência, das quais podemos encontrar um modelo de descrição nos fenomenólogos alemães Alfred Schütz e Thomas Luckmann (1979-1984). De acordo com esse modelo, os indivíduos constituem no decorrer das situações e dos eventos que eles vivem (erleben) uma "reserva de conhecimentos disponíveis" que eles utilizam como sistema de interpretação de suas experiências passadas e presentes e que determina igualmente a maneira pela qual eles antecipam e constroem as experiências futuras. É essa dimensão de "processo contínuo" da experiência entre passado, presente e futuro que John Dewey tinha revelado e descrito (1938) e que the tinha feito dizer que "a experiência é a própria vida".

Estes "saberes da experiência" ou "recursos biográficos" são armazenados na reserva de conhecimentos disponiveis sob a forma de estruturas de ação generalizadas que formalizam conforme uma lógica biográfica as experiências anteriores e pressupõem as experiências futuras, (ALHEIT, HOERNING, 1989). É

5 «A pessoa, entendida como personagem de sua narrativa, não é uma entidade distinta de suas " experiências ". Bem ao contrário: ela partilha o regime da identidade dinâmica própria à história contada. A narrativa constrói a identidade do personagem que chamamos sua identidade narrativa, construindo a da história contada. É a identidade da história que faz a identidade do personagem» (RICOEUR, 1990, p. 175) 
então a partir desses saberes tipizados e da estrutura de conhecimento que eles compõem que somos capazes de categorizar e integrar (ou não) o que percebemos e o que nos acontece, para acolher e reconhecer a experiência como "familiar", “idêntica", "análoga”, "nova", "estrangeira" etc. O sociólogo alemão Peter Alheit (2009, p. 79) desenvolveu a noção de biograficidade para explicar essa capacidade de integrar novas experiências àquelas que já tivemos. Nós compartilhamos com os outros e às vezes com muitos outros - situações que nós poderíamos externamente definir como similares ou idênticas. Mas, para cada um de nós, cada situação e cada experiência é singular, cada um de nós tem o seu modo particular de vivê-la, de lhe dar sua forma e sua significação. Essa singularidade só pode ser compreendida por meio da lógica interna, biográfica, de nossas experiências anteriores e como elas configuram nossa apreensão do presente e do futuro.

A biograficidade é, assim, o código pessoal segundo o qual "lemos" e "falamos" as novas experiências, das quais nós nos "apropriamos" (aneignen). Todas as experiências não exibem a mesma biograficidade. Algumas são facilmente integradas e entram sem resistência em nosso capital experiencial ou biográfico, porque elas reproduzem experiências anteriores e que podemos re-conhecê-las. Outras experiências exigem um trabalho de ajustamento, de interpretação, porque elas não correspondem exatamente aos esquemas de construção que as experiências passadas nos permitiram capturar. Enfim, no cotidiano da existência, muitas situações que vivemos não incitam nossa consciência ativa porque elas correspondem aos scripts repetitivos dos meios sociais e culturais. Mas, independentemente do grau de consciência ou de automaticidade ao qual responde o processo de biografização da experiência, este está, no entanto, sempre presen- te, garantindo a integração da experiência que acontece na temporalidade e a historicidade própria da existência singular.

Tal é, pois, o campo de saber da pesquisa biográfica articulado em torno do fato biográfico considerado em si mesmo e explorado por meio da atividade biográfica e dos processos de biografização. Um tal campo pode ser apreendido sob vários ângulos: ele pode convocar um olhar antropológico, suscitar abordagens sócio-históricas, ser abordado sob o ponto de vista da literatura e das escritas de si, fomentar estudos linguísticos e discursivos; e pode também - e este é o ponto de vista ao qual nos atemos essencialmente aqui - contibuir para esclarecer as dinâmicas multirreferenciais da constituição individual em todas as suas dimensão psíquica e social, psíquica e simbólica, política e educativa.

\section{Como a pesquisa biográfica constrói seu saber? Uma "ciência" do singular?}

Se tal é o saber específico ao qual tende a pesquisa biográfica, como ela o alcança, em que a constituição deste saber requer modos de pesquisa específicos? 0 investigador em pesquisa biográfica só pode acessar "um saber biográfico" pelas entradas que the dão os sujeitos no processo de biografização aos quais eles se dedicam. Estes, como já dissemos, podem assumir uma pluralidade de manifestações - mentais, comportamentais, gestuais -, mas a mediação privilegiada para acessar as modalidades singulares segundo as quais o sujeito biografa/biografiza suas experiências é, sem contestação, a atividade linguageira, a fala que o sujeito tem sobre si mesmo. Dentre todas as formas do discurso (descritivo, explicativo, argumentativo, avaliativo etc.), um lugar particular é reconhecido ao discurso narrativo, na medida em que o narrativo, pe- 
las suas características específicas, é a forma de discurso que mantém a relação mais direta com a dimensão temporal da experiência e do agir humano.

Expusemos em outras obras (DELORYMOMBERGER, 2014) o problema epistemológico e metodológico que colocado o recurso à narrativa, na dificuldade de apreender o que está em jogo entre "o ato de viver", "o ato de contar" e o texto que é o produto da atividade narrativa. Na e pela narrativa, o sujeito executa um trabalho de configuração e interpretação - de dar forma e sentido - da experiência vivida. A trama narrativa tem então uma dimensão performativa ${ }^{6}$ : ela age, ela produz a ação, e a ação que ela produz interfere no texto enquanto forma, mas também interfere no agir humano a que se refere no texto. As duas dimensões da formatação textual e de configuração da ação são consubstanciais. A narrativa não é então apenas o produto de um "ato de narrar", ela tem também um poder de efetivação sobre o que ele narra. É o que fundamenta o interesse principal da pesquisa biográfica para a narrativa, uma vez que esta, pelas operações de configuração e de metabolização que implementa, é um poderoso "ator" de biografização.

Lembramos também que, se a questão metodológica é inerente à pesquisa qualitativa em geral e aos estudos empíricos a que ela conduz (PAILLÉ \& MUCCHIELLI, 2008; OLIVIER de SARDAN, 2008), ela está no âmago da pesquisa biográfica, à medida em que esta se fixa como objeto a gênese individual do social nos processos de biografização. Tomada entre a singularidade, de certa forma, definicional, de seu objeto e a necessidade de uma formalização científica, a pesquisa biográfica deve se ater a uma posição - epistemológica e metodológica - que the permita não apenas con-

6 É dito perfomativo um enunciado que efetiva, que " realiza » o ato que ele significa: por exemplo, dizer «Eu prometo» ou «Eu juro» ou «Eu te batizo», é efetivar o ato da promessa, do sermão ou do batismo. ciliar essas duas exigências, mas responder empiricamente à pergunta que ela apresenta teoricamente, a saber, a fabricação "do mundo interior do mundo exterior", a metabolização e a apropriação pelo indivíduo - e por um indivíduo necessariamente singular - dos ambientes de todo tipo que são os seus.

Nessa empreitada, a pesquisa biográfica, longe de se opor ao indivíduo - a subjetividade individual - e o social como duas entidades separadas que deveriam se enfrentar, concentra-se, ao contrário, em manter juntos os dois termos de uma relação de instituição recíproca. O biográfico não é apenas um espaço de mediação e de articulação entre o individual e o social: ele é simultaneamente o lugar de uma instituição do indivíduo e de uma realização social, no âmbito da sua produção recíproca. Fixando para si como objeto os modos de constituição do indivíduo enquanto ser social singular, a pesquisa biográfica deve a si mesma, assim, com-preender, dizendo de outra forma, tomar em conjunto o que constitui precisamente a interface que ela se propõe a analisar e compreender: ao mesmo tempo, a agentividade individual e a estrutura social, a experiência singular e os "quadros da experiência", a "sociedade vivida" e a "sociedade constituída". O tornar-se biográfico é sempre o produto de uma interação entre a ação dos indivíduos e o determinismo das estruturas, e a maneira pela qual as pessoas explicam pela narrativa (se explicam a si mesmas) vias e processos pelos quais elas se constituíram não pode deixar de recortar as estruturas sincrônicas e diacrônicas que moldam os percursos individuais. No entanto, tomando em conjunto os dois polos da relação indivíduo-sociedade, o que procura capturar a pesquisa biográfica é a configuração singular de fatos e de situações, de crenças e de representações, de valores e de afetos segundo a qual os sujeitos tramam sua existência, são as construções de 
forma e de sentido que eles dão a suas experiências.

Portanto, quando o pesquisador (o investigador em pesquisa biográfica) instaura um espaço no qual narrativas poderão ser tomadas e entendidas, é em outra situação e em outra disposição que o sociólogo (ou o historiador, o demógrafo, o geógrafo do humano etc.) quando este "recolhe narrativas": para o sociólogo, as narrativas são materiais que vão permitir desvencilhar e constituir dados, incluindo qualitativos sobre as representações, as crenças, as práticas, os valores das categorias de populações que ele estuda. Estes elementos compõem o cenário social e cultural que informa e atravessa as existências e as experiências individuais, e, como tal, eles não são estrangeiros ao pesquisador em pesquisa biográfica. Mas o "interesse de pesquisa" deste último está em outro lugar: ele está naquilo que faz a narrativa, ele o traz para tentar entender como a narrativa ao mesmo tempo produz e permite vislumbrar a construção singular que um indivíduo faz de uma existência e de uma experiência, elas também singulares, que integram e se apropriam desses elementos coletivos.

\section{A construção partilhada de um saber do humana}

Ora, esta compreensão só pode ser o fruto de uma construção partilhada. O saber do singular ao qual tende a pesquisa biográfica só pode ser construído em um processo de pesquisa engajada no qual estão comprometidos juntamente os pesquisadores e as pessoas sobre/com as quais eles investigam. Franco Ferrarotti, interrogado em uma recente entrevista sobre a posteridade da concepção que ele defendia do "método biográfico" em seu livro fundador História e histórias de vida ([1983] 2013a), responde:
O método biográfico [...] leva o pesquisador a reconhecer que ele não sabe, que ele só pode começar e saber com os outros - com as pessoas -, com o saber das pessoas, e especialmente com o saber que seus interlocutores - ou seus "interagentes" - constroem com ele nas tomadas de fala, nas conversações, nas narrativas. [...] E isso exige estar em contato imediato com as pessoas ou os grupos sobre os quais se investiga, desenvolver relatos de interação, uma relacão interpessoal complexa e recíproca, na qual o pesquisador é ele próprio um "pesquisado". E, de fato, essas pessoas participam da pesquisa tanto quanto você e é por esta razão que se pode falar de coconstrução ou construção partilhada. Nessa interação de pesquisa, não há um investigador ou um observador que conhece e um investigado ou um observado que é conhecido. Como sabemos, o observador está completamente envolvido no campo de seu objeto que é nele mesmo modificado. 0 conhecimento não tem por objeto outro que não a interação recíproca entre observador e observado, é um conhecimento a dois que se constrói em uma interação, em uma intersubjetividade." (FERRAROTTI, 2013b , p . 23).

Os seres humanos não são "dados" que se poderia conhecer a partir do olhar exterior e objetivo há muito tempo pretendido pelo saber positivista das ciências naturais; são "processos em desenvolvimento", seres ancorados no espaço e no tempo, "sujeitos móveis e incertos" (FERRAROTTI, 2011). Toda ciência humana, toda pretensão ou ambição de construir um "saber do homem" (e não um "saber sobre o homem") deve, portanto, incluir em seus fundamentos epistemológicos assim como em seus princípios metodológicos essa dimensão processual, essa ancoragem contextual, esse caráter de imprevisibilidade. Esse saber do homem só pode então resultar de uma ciência da incerteza (FERRAROTTI, 2005), ancorada em uma ecologia dos saberes ${ }^{7}$. E, como o pesqui-

7 Sobre esse tema, leremos com muito interesse as ligações que Elsa Lechner (2012) faz entre as posições de Franco Ferrarotti e o paradigma da " ecologia dos saberes " desenvolvido pelo sociólogo português Boaventura de Sousa Santos. 
sador "de ciência humana" participa por sua própria humanidade de todas essas características, que é inevitavelmente e, sem dúvida, indissociavelmente "tomado" e "compreendido" em seu "objeto de estudo", que seu desejo, sua vontade, sua busca pelo saber encontrem o desejo, a vontade, a busca do outro, sua pesquisa só pode ser ela mesma um processo de mediação, de intercessão, de exploração de um entre, a emoção e o movimento de uma lacuna ${ }^{8}$, que supõem, envolvem, convocam a presença do outro, reconhecem sua parte criativa no momento de um "viver comum" e no espaço de um "falar junto". A pesquisa em ciências humanas, se é fiel a si mesma e coerente com o que pretende, tem de singular que ela só pode ser uma busca partilhada, só pode ser construída na colaboração - no trabalho realizado em conjunto - pessoas ou grupos que são simultaneamente entrevistadores e entrevistados e que vivem, agem, falam, constroem em comum o que constitui entre eles a obra de conhecimento. Trata-se, portanto, para retomar as palavras do antropólogo Éric Chauvier juntando-se plenamente ao propósito de Franco Ferrarotti, de "conceber o processo da investigação como o próprio objeto da investigação" (2011, p. 56). Convidando a uma verdadeira "conversão do olhar", essa concepção de uma ciência humana como experiência vivida e um discurso partilhado deve conduzir à saída definitiva de um paradigma científico onde as posições de "objeto" e de "sujeito" são estabelecidas como princípio e de maneira invariável, onde o universal se opõe ao singular como o geral ao particular.

\section{Um espaço de pesquisa clínica}

Por seu objeto e seu método, já o dissemos, a pesquisa biográfica envolve abordagens nas quais entrevistadores e entrevistados estão em

8 Nessa matéria, o pensamento do sinólogo François Jullien (2012) não pode deixar de ser convocado. um processo comum de investigação e de conhecimento que, se não visa o mesmo saber para uns e outros, pressupõe sua interdependência e sua colaboração. Como o escreve com muita pertinência Anne Dizerbo em um trabalho inédito:

A pesquisa biográfica é em essência colabora-
tiva, uma vez que implica ao mesmo tempo um
trabalho do sujeito com o qual o pesquisador
entra em relação, e um trabalho do pesquisa-
dor. Mas esse trabalho não é da mesma natu-
reza para uns e outros. Simplificando: os sujei-
tos trabalham para dar sentido às suas expe-
riências; os pesquisadores trabalham para dar
sentido ao trabalho que fazem os sujeitos ao
darem sentido às suas experiências.

Como tal, o espaço de pesquisa da pesquisa biográfica só pode ser um espaço de relacionamento ou como diz ainda Ferrarotti, de "dinâmica relacional", como evidenciado pela centralidade dada à fala dos atores e à "interação social" que constitui particularmente a situação da entrevista:

Restauremos à entrevista biográfica toda a sua espessura de interação social. As narrativas biográficas das quais nos servimos não são monólogos face a um observador reduzido ao papel de suporte humano de um gravador. Cada entrevista biográfica é uma interação social complexa, um sistema de papéis, de expectativas, de imposições, de normas e de valores implícitos, frequentemente também de sanções. [...] Ligações entre observador e observado em uma relação recíproca, conhecimento científico exigindo a hermenêutica de tal interação, narrativa biográfica percebida como ação social, a entrevista biográfica nos parece ser um exemplo perfeito do polo clínico das ciências humanas. (FERRAROTTI, 2013a, p. 54 e 56)

Este "polo clínico", que constitui aos olhos de Franco Ferrarotti a entrevista biográfica, nós o retomaríamos de bom grado por nossa conta, se entendemos por clínico o espaço de uma relação onde se implementam um cuidado $e$ uma escuta do outro atentos (atenciosos) ao 
que está em jogo para a pessoa em uma busca das formas e do sentido de suas experiências?. A relação que é estabelecida na entrevista de pesquisa biográfica abre efetivamente um $d u$ plo espaço heurístico: aquele do pesquisador e o do objeto de sua pesquisa, mas também aquele do " pesquisado » chamado, pela narrativa à qual ele é convidado, a implementar um trabalho de pesquisa de formatação de sua experiência. Essa dupla empreitada de pesquisa, aquela do pesquisado em posição de pesquisador dele mesmo, aquela do pesquisador cujo objeto é o de compreender o trabalho do entrevistado sobre ele mesmo, convida a questionar as posições do pesquisador e do pesquisado, do questionador e do questionado. Quem é o verdadeiro questionador na "entrevista de pesquisa biográfica"? Aquele que fala e conta de si ou aquele que escuta e que recebe? Aquele que é a prova de sua narrativa e, por meio dela, de suas formas de existência, ou aquele que recolhe as provas deste questionamento? E quem é o verdadeiro entrevistado? Aquele que, por meio de sua narrativa, implementa a hermenêutica prática da sua existência ou aquele que procura ouvir e entender esse trabalho de interpretação? Eles não são, um e outro, entrevistador e entrevistado, pesquisador e pesquisado? Não têm eles, um e outro, sua parte na construção de uma obra de conhecimento que, por não ter o mesmo sentido para um e para o outro, só é possivel no partilhamento do que eles fazem?

Essa dimensão relacional e clínica que está no cerne de nosso espaço de pesquisa questiona certamente nossas ações e nossos objetivos científicos, mas também a nossa responsabilidade ética e política. E, sem dúvida, devemos voltar um instante sobre o que nos compro-

9 O livro de Christophe Niewiadomski, Recherche biographique et clinique narrative [Pesquisa biográfica e clínica narrativa] (2012), oferece o quadro teórico para pensar esta dimensão clínica e nele desenvolver ilustrações esclarecedoras. mete, a nós pesquisadores, a nos engajar ao lidar com esse "tipo de material" tão particular que consiste no discurso dos atores. As entrevistas narrativas, as narrativas biográficas contribuem para constituir um conhecimento em situação, uma compreensão do interior das vivências humanas. Eles têm acesso à maneira como atores singulares vivem, pensam e agem em suas vidas dentro dos seus próprios contextos, contra os discursos dominantes e os saberes hegemônicos, eles fazem acontecer "o ponto de vista do sujeito" e os tipos de saber que ele elabora ao longo de sua experiência: um saber que se constrói sempre em um lugar historicamente, socialmente e semioticamente situado e que remete - para usar um termo de Donna Haraway - à perspectiva "incorporada" dos lugares, das condições e dos pontos de vista tanto coletivos quanto singulares a partir dos quais ele foi dito.

O que fazer então desses "saberes incorporados" do vivido e da experiência? Como tratá-los, como dar-lhes sentido? Como articulá-los a outras formas de saberes? O que talvez seja uma maneira de dizer mais radicalmente: o que fazer dos "sujeitos", o que fazer da fala dos sujeitos no estudo e no tratamento das questões que lhes concernem? Acho que a resposta - muito simples intelectualmente e muito complexa se quisermos traduzi-la em fatos - está na questão: é necessário fazer com as pessoas, é necessário fazer com os sujeitos. Para os pesquisadores, isso significa estabelecer dispositivos de pesquisa participativa, de compartilhamento e de hibridação dos saberes, de coconstrução do conhecimento; para os responsáveis institucionais e políticos, isso significa estabelecer espaços e práticas de governança democrática que não se satisfaçam mais com a delegação representativa única, mas que integrem a fala, a opinião e a capacidade de decisão dos atores envolvidos. Se houver um horizonte utópico, é o horizonte 
que dá o meu sentido à pesquisa biográfica, além de seu valor científico, sua plena dimensão de clínica política.

\section{Conclusão}

Após essa revisitação dos nossos objetos e de nossos processos de saber, eu gostaria de concluir retornando para o que me parece poder esclarecer o uso que fazemos dos termos pesquisa biográfica e pesquisa biográfica em educação para denominar nossa corrente de investigação.

Ao lado do campo estabelecido da formação e da educação, é tudo o que faz "o estabelecimento humano", isto é, retomando as palavras de Lucien Sève, "o conjunto dos processos biográficos pelos quais o indivíduo da espécie humana torna-se psiquicamente societário do gênero humano" (SĖVE, 2008, p. 105), que constitui o espaço destinado à pesquisa biográfica, uma vez que ela se propõe a tarefa de apreender a experiência subjetiva. Traduzido para a língua ético-política do sujeito e da Cidade, este longo processo de individuação / socialização, que é a marca do desenvolvimento humano e que atravessa todos os espaços da ação e da experiência humana, nada mais é do que o movimento de educação pelo qual o ser humano sai da sua minoria ${ }^{10}$. Neste sentido, a pesquisa biográfica concebe "a educação" como uma das dimensões constitutivas do fato e do tornar-se humanos: no espaço social e no tempo da existência, trata-se sempre de compreender como se forma e se constrói o ser social singular.

São, por outro lado, os trabalhos conduzidos sob o título da pesquisa biográfica sobre as relações entre processos de construção biográfica e processos de aprendizagem e de

10 Sobre esse tema eminentemente Kantiano, ver o belo livro de Cynthia Fleury, Os insubstituíveis: " Individuar-se, tornar-se Sujeito, necessitamos sair do estado de minoria no qual nos encontramos, naturalmente e simbolicamente. » (2015, p. 16) formação que mostram os vínculos estreitos entre educação e individuação, educação e socialização, e que levam a redefinir a noção de educação, concebida como um processo amplo que abrange todas as formas da experiência vivida e adquirida. Da dimensão global do desenvolvimento individual no espaço social e a vida pessoal aos episódios específicos vividos nas instituições de ensino e de formação, das formas experienciais de formação e de aprendizagem encontradas na atividade profissional e na vida social ao papel dos ambientes e das mediações sócioculturais, são todas as experiências, todos os espaços, todos os tipos de formação e de aprendizagem, formais, não formais e informais se disseminando ao longo da vida, que compõem o campo de uma aprendizagem biográfica referente à globalidade da pessoa.

Pela própria definição de seu projeto, a pesquisa biográfica encontra-se quase sempre ao lado de formas de pesquisa que, conduzidas ou co-construídas com os atores, perseguem segundo os casos e em diferentes graus, objetivos individuais e coletivos de formação, de valorização dos recursos e das potencialidades, de produção e partilha dos saberes, de emancipação, de poder de agir, de transformação social e política.

Esta preocupação com a "educação humana" dá à pesquisa biográfica uma responsabilidade particular, que não é apenas de ordem científica, mas também ética e política. Se a "fala de si", sob todos os seus registros e em todas as suas diversidades, constitui o material privilegiado de um saber biográfico, ela é também o vetor pelo qual os seres humanos acessam a um saber e a um poder deles mesmos que lhes dão a capacidade de se desenvolver e de agir enquanto "sujeitos" no meio dos outros e no seio da cidade. Neste ponto, onde o vocabulário supostamente neutro da ciência cede diante da linguagem da ética e da 
política, a pesquisa biográfica não pode deixar de ser contestada pela divisão social e geográfica muito desigual dos recursos diretamente relacionados à capacidade das pessoas de elaborar e de fazer entender sobre elas mesmas em uma linguagem aceitável, de acessar aos meios de expressão e afirmação que os farão reconhecer socialmente e politicamente. Tais questões remetem a pesquisa biográfica ao que constitui a dimensão ética da sua abor-

\section{Referências}

ALHEIT, P. « Diskurspolitik » : Lebenslanges Lernen als postmodernes Machtspiel ? [« Politique du discours »: l'apprentissage tout au long de la vie comme enjeu de pouvoir dans la postmodernité ?]. In. ALHEIT, P.; FELDEN, H. (Hrsg.). Lebenslanges Lernen und erziehungs-wissenschaftliche Biographieforschung [Apprentissage tout au long de la vie et recherche biographique en éducation]. Wiesbaden: VS Verlag für sozialwissenschaften, 2009. p. 77-88.

ALHEIT P., HOERNING E. (Hrsg). Biographisches Wissen. Beiträge zu einer Theorie lebensgeschichtlicher Erfahrung [Savoirs biographiques. Contributions à une théorie de l'expérience totu au long de la vie]. Frankfurt/New York: Campus, 1989.

ALHEIT, P., DAUSIEN, B. Die biographische Konstruktion der Wirklichkeit. Überlegungen zur Biographicität des Sozialen. [La construction biographique de la réalité. Réflexion sur la biographicité du social]. In E. M. Hoerning (dir.), Biographische Sozialisation. [Socialisation biographique]. Stuttgart: Lucius \& Lucius, 2000.

CERTEAU, M. de. L'invention du quotidien 1. Arts de faire. Paris: Gallimard Folio, 1990.

CHAUVIER, É. Anthropologie de l'ordinaire. Une conversion du regard. Paris: Anacharsis Éditions, 2011.

DELORY-MOMBERGER, C. Histoire de vie et recherche biographique en éducation. Paris: Anthropos, 2005.

DELORY-MOMBERGER, C. (2007). Biographisches Ler- dagem, ou seja, a saber, a preocupação de esclarecer as condições sobre as quais a fala de si pode constituir para o sujeito um vetor de apropriação de sua história e de seu projeto e contribuir dessa forma para uma perspectiva "emancipatória" das pessoas e dos grupos humanos. Por todas essas razões, teremos compreendido que a pesquisa biográfica tal como a entendemos só pode ser teorizada e praticada como pesquisa biográfica em educação.

nen [Apprentissage biographique]. In M. Göhlich, C. Wulf, J. Zirfas (dir.). Pädagogische Theorien des Lernens [Théories pédagogiques de l'apprendre]. München: Beck Verlag, 2007. p. 142-152.

Delory-Momberger, C. La recherche biographique. Projet épistémologique et perspectives méthodologiques. In. De la recherche biographique. Fondements, méthodes, pratiques. Paris: Téraèdre, 2014, p. 73-94.

DEWEY, J. Experience and Education. New-York: The MacMillan Company, 1938

FERRAROTTI, F. On the science of uncertainty. The biographical method in social research. Oxford/ New York: Lexington Books, 2005.

FERRAROTTI, F. Las historias de vida como método. Acta sociológica, 56, 95-119, 2011.

FERRAROTTI, F. Histoire et histoires de vie. Préface de Georges Balandier, introduction de Antonella de Vicenti et Gaston Pineau. Paris: Téraèdre, 2013a [1983].

FERRAROTTI, F. Partager les savoirs, socialiser les pouvoirs. Entretien avec Christine Delory-Momberger. Le sujet dans la Cité. Revue internationale de recherche biographique, 4, 19-27, 2013b.

GIUST-DESPRAIRIES, F. Le désir de penser. Construction d'un savoir clinique. Paris: Téraèdre, 2004.

JULLIEN, F. L'écart et l'entre. Leçon inaugurale de la chaire sur l'altérité. Paris: Éditions Galilée, 2012. 
LECHNER, E. La recherche biographique aujourd'hui. De la science de l'incertitude au savoir ancré. Le sujet dans la Cité. Revue internationale de recherche biographique, 2, 214-226, 2012.

NIEWIADOMSKI, C. Recherche biographique et clinique narrative. Entendre et écouter le Sujet contemporain. Toulouse: Érès, 2012.

OLIVIER DE SARDAN, J.-P. La rigueur du qualitatif. Les contraintes empiriques de l'interprétation socio-anthropologique. Louvain-la-Neuve : Academia -Bruylant, 2008.

PAILLE, P. \& MUCCHIELLI, A. L'analyse qualitative en sciences humaines et sociales. Paris : Armand Colin, 2008.

RICOEUR, P. Temps et récit I. Paris: Seuil, 1983.
RICOEUR, P. Soi-même comme un autre. Paris: Seuil, 1990.

SCHAPP, W. Empêtrés dans des histoires. L'être de l'homme et de la chose, Traduction de J. Greisch. Paris: Éditions du Cerf, 1992.

SCHÜTZ, A. Der sinnhafte Aufbau der sozialen Welt [La construction sensée du monde social]. Frankfurt/M.: Suhrkamp, 1981.

SCHÜTZ A., LUCKMANN T. Strukturen der Lebenswelt [Structures du monde-de-vie]. 2 vol. Frankfurt/M : Suhrkamp, 1979 et 1984.

SEVE, L. Penser avec Marx aujourd'hui. Tome 2: « L’homme »? Paris : La Dispute, 2008.

Recebido em: 05.01/2016

Aprovado em: 04.02.2016

Christone Delory-Momberger é professora da Faculdade de Ciências da Educação da Univerisdade de Paris 13 Sorbone Paris Cité. Diretora do Centro de Pesquisa Interuniversitário EXPERICE. Presidente do Colégio Internacional de Pesquisa Biográfica em Educação e Diretora Científica da Revista Internacional de Pesquisa biográfica - o Sujeito na Cidade. E-mail: christine.delory@lesujetdanslacite.com 